\title{
New varieties of English: Issues of incomprehensibility and unintelligibility
}

\author{
Z. N. Patil \\ Professor Emeritus
}

\begin{abstract}
:
The present article discusses new varieties of English with reference to intelligibility and comprehensibility. It has been observed that new varieties of English display deviant phonological features. Speakers of these varieties insert a sound, delete a sound, substitute a sound, and rearrange sounds when they pronounce certain words. Moreover, they use deviant word stress patterns. These things affect the intelligibility of their speech. The new varieties differ at the level of discourse as well; the content and language used to perform certain speech acts such as coaxing, responding to questions, etc., may result in miscommunication. Thus, unintelligibility is a result of mother tongue interference and incomprehensibility is a result of mother culture interference. The article illustrates unintelligibility and incomprehensibility using examples from non-native varieties of English.
\end{abstract}

\section{Context}

In this article, I discuss two significant aspects of new varieties of English. These aspects are incomprehensibility and unintelligibility. However, this does not mean that the dialects of native British and American English are invariably mutually comprehensible and intelligible. The article discusses the issues of incomprehensibility and unintelligibility against the background of three premises. First, it is not only the new varieties of English but also the native varieties that may be mutually incomprehensible and unintelligible. Secondly, the onus for being comprehensible and intelligible is on the shoulders of not only the nonnative speaker of the English language; but equally on the shoulders of the native speaker. Thirdly, the linguistic, physical and psychological contexts help us to decipher unintelligible utterances and understand incomprehensible utterances; however, it is the responsibility of the speaker and the hearer to overcome unintelligibility and incomprehensibility.

\section{Introduction}

The English language has moved from its native habitat and spread its existence to new habitats. In the process of its spread it has changed itself not only formally but also 
functionally. It is in this context that Achebe, a Nigerian writer (1965, p. 29) feels that it is neither necessary nor desirable for him to use English like a native writer does. Achebe (1975, p. 62) wants the English language to carry the weight of his African experience. Obviously, the native variety in its unchanged form is incapable of serving that purpose. To achieve that objective, it will have to be new English, still in communion with its 'ancestral home' but altered to suit its new African surroundings. Ojaide (1987, pp. 165-167) is another Nigerian writer who professes that the English that he writes and speaks is neither mainstream British English nor American English, and that he cherishes this uniqueness. The sensibility that he expresses is African sensibility, which is different from Western and Asian sensibilities, though a little closer to the Asian sensibility. His writing, though in English, has its roots in Africa, not in England or North America. Being a cultural standard bearer of the African world, not of the British or Western world, he is free to manipulate English to his advantage. Soyinka (1993, p. 88) regards native English as a linguistic blade in the hands of the traditional cultural castrator, which black people have twisted to carve new concepts into the flesh of white supremacy. Sidhwa (2000), cited in Yoneoka (2002), sounds a similar note when he remarks that "the colonized have subjugated the English language, beaten it on its head and made it theirs, and in adapting it to their use, in hammering it sometimes on its head and sometimes twisting its tail, they have given it a new shape, substance and dimension".

Raja Rao (1938) echoes the views voiced by Achebe, Ojaide, and Soyinka. In the foreword to his celebrated novel titled Kanthapura he admits that "a language that is not one's own" is inadequate to express "the spirit that is one's own". He confesses that the various shades and omissions of certain thought-movement look maltreated in a foreign language. Perhaps it is because of this inadequacy that Dasgupta (1993, p. 201) labels English as an alien language, an aunt, not a mother. His contention is that even if Indians have been using and exploiting English, it has not got close to their hearts. It is not one of them although it is an important presence to be respected. Kourtizin (2000, cited in Lee 2005), holds a similar view of Japanese, which is not his first language: "English is the language of my heart, the one in which I can easily express love for my children; in which I know instinctively how to coo to a baby; in which I can sing lullabies, tell stories, recite nursery rhymes, talk baby talk. In Japanese, there is some artificiality about my love; I cannot express it naturally or easily. The emotions I feel do not translate well into the Japanese language."

It is this inadequacy of the other tongue that prompts Raja Rao to use the English language innovatively to make it approximate the Kannada rhythm. In keeping with his theme in Kanthapura he experiments with the language following the oral rhythms and narrative techniques of traditional models of writing. He breaks the formal English syntax to express the emotional upheaval that shakes the village of Kanthapura. The author's foreword to the novel almost spells out the postcolonial cultural agenda: "The telling has not been easy.... We cannot write like the English. We should not. We can write only as Indians. We have grown to look at the large world as part of us. Our method of expression therefore has to be a dialect, which will some-day prove to be as 
distinctive and colourful as the Irish or the American. Time alone will justify it."

These creative writers are justifying the need to modify the English language at the formal and functional levels to convey the nuances of the cultures that have adopted English as a vehicle of expression. Some of these properties and functions that these creative writers are hinting at may cause incomprehensibility and unintelligibility.

Before I illustrate properties and functions that hamper comprehension and intelligibility, let me distinguish between unintelligibility and incomprehensibility. Unintelligibility is basically a phonological and phonetic problem. Unintelligibility refers to the qualities of accent that result in failure to decipher pronunciation, articulation of sounds and word stress, and consequently to understand meanings and messages. Comprehensibility, on the other hand, is a pragmatic problem. We understand the words, we understand the accent, we understand the literal meaning; but we fail to understand culture-bound, culturally determined, contextual meanings. Thus it is basically a pragmatic failure. Smith and Nelson (1985), cited in Taylor (2003), distinguish between intelligibility, comprehensibility, and interpretability. For them intelligibility has to do with word or utterance recognition, comprehensibility with word or utterance meaning, and interpretability with illocutionary force.

\section{Incomprehensibility}

Let me illustrate using Indian English as example formal properties that may cause incomprehensibility. These formal properties fall under vocabulary, grammar and discourse.Vocabulary is one factor that causes incomprehensibility. There are two aspects of vocabulary that create incomprehensibility problems for users of English who are unfamiliar with other varieties of English such as Indian English. For example, Indian users of English have added a few words to the lexicon of the language. Some of these words are 'prepone' for 'advance', 'co-brother' for one's 'wife's sister's spouse', 'godown' for 'warehouse', 'opticals' for 'glasses', 'lakh' for 'a hundred thousand', 'crore' for 'ten million', 'bunk classes' for 'play truant' and so on. In addition, there are certain English words which are used in senses different from those in British and American varieties; for example, 'hotel' is used to mean 'restaurant', 'shift' is used to mean 'move into a new house', 'reach' is used to mean 'arrive', 'standard' is used to mean 'grade'. A listener unfamiliar with this variety of English may not understand the intended meanings of these words or may misunderstand them. Similarly, the reverse use of the verbs 'give' and 'take' in the context of an examination may baffle a foreign listener. In the so-called standard variety, teachers 'give a test' and their students 'take a test'. In Indian variety, the expressions are frequently reversed. The hearer may find it difficult to know as to who the tester and the testee is. Let me cite an example from Vietnamese variety. One case in point is the use of 'come' and 'go' in Vietnamese variety of English. In standard variety of English, 'go' means moving to a place that is far from the speaker and the listener and 'come' means moving to a place that is nearer to the hearer. For example, a student may say to his teacher: "May I come in, Sir?" and "Sir, may I go home now?" In the first case, the student is moving nearer to the teacher; in the second case, the student wants to move away from the teacher. This is the normal use in 
English. But, in Vietnamese variety of English, the use is reversed. The student usually says to the teacher who is in school with him. "Excuse me, Sir. May I come back home now? And yes, I cannot go to school tomorrow" (Patil 2002, pp.14-16). Japanese speakers of English also tend to use these two verbs for reverse meanings.Let us look at one more example. Like the words 'come' and ' $\mathrm{go}^{\prime}$ ', most Vietnamese students use the words 'bring' and 'take' in a reverse sense. In British English when I 'bring' something I carry it from another place to the place where the hearer is. Similarly, when I 'take' something, I take it from where the hearer and I are to another place. But most Vietnamese students use the two words in an opposite way. As a teacher, I often heard my students say, "Excuse me teacher. I don't have this book at home. Can I bring it for a week, please?" and "I'm sorry teacher. I forgot to take the book that I brought from you last week. I'll take it tomorrow." Now, the important point here is how do these readers interpret 'come' and 'go' and 'bring' and 'take' when they encounter them in a reading passage? Do they interpret them the English way or the Vietnamese way? My experience is that elementary and intermediate level Vietnamese learners of English interpret these words the Vietnamese way. They need to be told time and again that the usual meanings of 'come' and ' $g o^{\prime}$ are different from the meaning they attach, and so is the case with 'bring' and 'take'.

Variant grammar is another factor that may lead to incomprehensibility. Some grammatical features of Indian variety of English are extensive use of the present progressive (e. g., "I am having very kind and considerate parents.", "No I am not from Pune; I am coming from a tiny village near Pune."); omission of the definite article (e. g., "I am only support my mother-in-law has."); plural forms of uncountable nouns (e. g., "I bought some furnitures last week."); plural forms of nouns that do not take the plural marker (e. g., "When we were landing at Delhi airport, we saw several aircrafts flying over New Delhi."); and invariable question tags (e. g., "You have done the homework, isn't it?"). These formal properties may cause comprehension problems.

Here are some more examples of incomprehensible English. Many speakers of Indian variety of English produce utterances like the following:

"Like you, I cannot speak English very well."

What the speaker wants to say is that the addressee can speak English very well, but the speaker cannot. But the unintended meaning of the speaker's utterance is exactly opposite. The speaker's utterance means that the speaker as well as the addressee cannot speak English very well.
A: "You haven't been to London, right?"
B: "Yes."
Or
B: “No."

Here there are two speakers. The first speaker (A) wants to know whether the second speaker (B) has been to London or not. The first speaker's utterance is negative primarily assuming that $B$ has not been to London. However, B can answer it either in the negative or in the affirmative. In 
standard British and American English an affirmative response would mean that the speaker has been to London ("Yes, I have been to London"). However, in Indian English it means exactly the opposite. It means that $\mathrm{A}$ assumes that $\mathrm{B}$ has not been to London and what $\mathrm{s} /$ he assumes is right. It does not mean that $\mathrm{B}$ has been to London. Thus "yes" in this case implies agreement with the first speaker (speaker A). Similarly, in British and American varieties a negative response would mean that the speaker has not been to London. In these varieties B says something like this: "You assume that I have not been to London. No, I haven't been to London." But in Indian English it means "You think that I have not been to London, but I have been to London. So, I disagree with you or that your assumption is wrong." Thus 'No' implies disagreement with speaker A.

Omission of an article may also lead to incomprehension. As we know, 'a few' has different meaning from 'few' and 'a little' has different meaning from 'little'. 'Few' and 'a few' have countable meanings; 'few' means 'almost none' whereas 'a few' means 'some'. 'Little' and 'a little' have uncountable meanings; 'little' means 'almost no/ nothing' whereas 'a little' means 'some'. The speaker's lack of knowledge of this distinction results in a wrong choice. There is a mismatch between speaker's intention and listener's comprehension. The speaker intends to say or mean 'almost no sugar in the kitchen' or 'almost no students in the classroom' but chooses 'a little sugar in the kitchen' and 'a few students in the classroom' respectively. The speaker's choice of 'a little' and 'a few' are semantically positive, but the meanings that $\mathrm{s}$ / he wants to convey are negative. When the listener who is aware of the semantic distinction resulting from the grammatical difference listens to the speaker, s/he interprets the expressions as positive. Thus there is a mismatch between what the speaker wants to convey and the grammatical choices s/he makes. A similar thing happens at the interpretation stage. The listener hears positive expressions such as 'a little' and 'a few' and naturally interprets them as having positive meaning. Thus there is a conflict between the speaker's intention and the listener's reception. This mismatch leads to confusion at the comprehension level.

Another stumbling block in comprehensible communication is the use of information seeking interrogatives in place of interrogatives that express irritation, annoyance, accusation, surprise, etc. As we know, there is a semantic difference between the two. In the interrogatives expressing special meanings 'what', 'where', 'who', etc. change to 'whatever', 'wherever', 'whoever', etc. Let's look at the following sets of sentences.

\section{Information seeking interrogative sentences:}

1. What did you do?

2. Who did you go with?

3. Where were you yesterday?

Interrogative sentences with special meanings:

1. Whatever did you do?

2. Whoever did you go with?

3. Wherever were you yesterday?

Certain features of spoken discourse may also lead to incomprehension. For example, differing patterns of turn taking found in different cultures may cause incomprehension or rather confusion. 
In the first pattern, one speaker completes his/her turn and only then does another speaker begin his/her contribution. In the second pattern, there is a silence after the first speaker has finished his/her turn. This pattern is observed in Japanese culture. The pause between the two turns is interpersonally and socially significant. It is indicative of respect shown by the second speaker. The pause means that the second speaker thinks that the first speaker's contribution is so valuable that the second speaker needs time to understand its import. The third pattern shows interruption. These interruptions may not only be due to any urgency, but due to cultural acceptability. In the fourth pattern, two speakers talk simultaneously and demand the listener to listen and make sense of what they are talking about. In the fourth pattern, two speakers keep talking simultaneously. In the fifth pattern, more than two people talk together. This is a pattern most noticeably observed in debates, especially political debates, on some Indian TV channels.

Coaxing is another instance, which may cause incomprehension in a situation involving a foreign guest. An Indian host would like to continue coaxing even when the guest cannot eat any more. The host would say that the guest has eaten nothing, which may baffle the foreign guest. It is equally interesting to see what happens in a situation where the guest is an Indian and the host is a foreigner. In the Indian culture, it is polite to say 'no' to a second helping and 'no' here means, "I will have another helping only if you coax me again." However, if the foreign host interprets that 'no' literally and does not offer another helping, the guest may remain hungry.
Another strategy that may baffle a foreigner is that of attributing ownership. Thus, utterances such as "Be comfortable, this is your house" may confuse the foreign listener. Another strategy that may confuse foreigners is self-humbling. In Indian culture, whatever belongs to the speaker is ordinary and whatever belongs to the addressee is extraordinary. Thus, my house would be a humble hut or a cottage, and your house would be a palace, a bungalow. The question "May I know your good name please?" is a result of this strategy. The listener who is not familiar with the strategy of addressee-elevation and speaker-humbling may find this question rather puzzling. S/he may say, "Well, I have a first name, a middle name, a last name, a nickname and a pen-name. I don't have a 'good' name". The question unwittingly implies that the addressee has a good name and a bad name. So is the utterance "I am at your service". An Englishman will usually say, "May I help you?" or "What can I do for you?"

Quite often such utterances are translations of utterances from the speaker's mother tongue. Once I was participating in an international conference. After my presentation, a German friend shocked me when she described my ideas as 'the yellow of the egg' and my presentation as 'very pregnant'. What he meant was that my ideas were brilliant and that my presentation was very precise. Initially, I understood the literal meaning and was a bit amused, but when I comprehended the implied meaning I was comfortable.

\section{Unintelligibility}

Now let me illustrate features of Indian variety of English that may cause unintelligibility. This section examines the 
relevance of the construct of speech intelligibility in the light of two presuppositions. First, 'familiar social context, shared cultural background or schematic knowledge, and insider awareness of linguistic norms', 'a willing ear' (Nair-Venugopal 2003), and paralinguistic and nonverbal features such as intonation, facial expressions, eye contact, physical touch, social distance, posture and gesture (see Miller 1981, and Pennycook 1985, cited in Brown 1989) can facilitate intelligibility. Secondly, intelligibility is not a matter of 'either or'. In other words, it is not speaker-centred or listener-centred; it is interactional (Smith and Nelson 1985, p. 333). Non-native speakers have to be intelligible to native speakers; conversely, native speakers need to be intelligible to non-native speakers. In this context, let me mention the decision taken by the civil aviation authorities of India (The Times of India, February 10, 2006). According to this mandate, all expatriate pilots will have to pass a spoken English test, because as the source says, "We do not want to face a situation where these foreign pilots are not able to converse with the ATCs- Air Traffic Controllers. This can cause serious problems". This resolution comes years after a worst mid-air collision between a Saudi Arabian Airliner jet and a Kazhakstan cargo plane, caused by a pilot's poor understanding of English. As Toolan (1997) suggests, L1 and L2 speakers of English accommodate to one another's use of the language and share responsibility for intercultural communication. By the same token, the negotiation of meaning between non-native speakers of English with different linguistic backgrounds stresses the 'cooperative nature of lingua franca communication' (Meierkord 1998). These assumptions underpin the discussion of the issue of intelligibility of English as a global language.

Crystal (1997, p. 2) characterizes a global language as follows: "A language achieves a genuinely global status when it develops a special role that is recognized in every country". As Graddol (1997, p. 56) points out, the English language has two main functions in the world: it provides a vehicular language for international communication, and it forms the basis for constructing identities. The former function requires mutual intelligibility and common standards; the latter encourages the development of local forms and hybrid varieties. Given the forecast that English will remain a global language for several decades to come, we may then ask the question 'How will English change its form and role as an international link language?' Yano (2001, cited in Yoneoka 2002), predicts three possible outcomes for the future of English as a global language: (i) Acrolect-level local varieties of English may come into existence; (ii) English may diverge into many mutually unintelligible local varieties; (iii) it may diversify into a variety of mutually intelligible dialects except in writing. The first of these outcomes seems to be coming true. Attempts to codify the varieties have accorded them acceptance and prestige. We no longer subscribe to the rigid distinction between 'native' and 'non-native', and we look at the varieties in the spirit of equality and shared communicative responsibility. In fact, with the diversification of English, we are talking about training the native speaker to develop sensitivity towards intercultural communication.

Cathford (1950, as cited in Nair-Venugopal 2003), states that intelligibility depends on its realization of at least four out of five 
aspects: selection, execution, transmission, identification, and interpretation with an elaboration-effectiveness-which depend on the hearer's response matching the speaker's intent of purpose. As Jandt (2001, p. 29) puts it, the components of communication are source, encoding, message, channel, noise, receiver, decoding, receiver response, feedback and context. When receivers fail to decode a message, communication stops and responses can be quite diversified.

Most of the work done so far discusses intelligibility with reference to native speakers. As a result, non-native learners and speakers are supposed to emulate the native speaker model (Taylor 2003), because the native speaker is believed to be the sole owner of English. Hence it is the responsibility of the non-native speaker to work towards the native model (Smith 1987, p. xi). Scholars like Bansal (1969) held a one-sided perspective and thought of intelligibility with reference to external norms. They maintained that the nonnative varieties of English were not only different but also deficient and unintelligible. They took British and American varieties as standard, correct, prestigious, and intelligible and suggested non-native speakers of English emulate them. However, if English no longer belongs to the native speaker and the native speaker is no longer involved in many English transactions, perhaps this is no longer appropriate. As Nihalani (2000, p. 108) states, "The typical approach in this tradition is to use the native accent selected for comparison as a template, juxtapose it against a non-native accent, and identify the features that do not fit the template". This outlook has two implications. First, the non-native speaker should make effort to approximate the external norm set by the so-called standard variety to understand the native speaker and to be intelligible to him/her. Secondly, the native speaker is free from this responsibility. Thus, only one participant is obliged to make effort because s/he speaks a deviant variety.

The legitimization of new varieties of English has moved the debate on the issue of intelligibility from the one-sided position to a two-sided perspective. The latter perspective looks at communication between speakers of different varieties as a shared activity, a common pursuit to achieve mutual intelligibility. The central argument is that users of English as a lingua franca in international contexts should not look to native speakers of English for norms but should aim for mutual intelligibility among themselves (Jenkins 2000). It is in this context that McKay (2002) considers standards for English as an international language with reference to intelligibility and examines the lexical, grammatical, and phonological features of varieties of English. As Seidlhofer (2003) points out, "a general shift in curricular guidelines has taken place from correctness to appropriateness and intelligibility, but by and large intelligibility is taken to mean being intelligible to native speakers, and being able to understand native speakers".

Let us now discuss factors that cause unintelligibility. Nihalani (1997) states, "two foreigners of the same nationality can converse with mutual understanding in English using their own phonetic and phonological systems. They run a serious risk, however, of being quite unintelligible to a speaker of English from the outer or inner circle. The learner must therefore adopt certain basic features of English in his pronunciation if he is to acquire a linguistic tool of international use. It is commonplace 
knowledge that various native varieties of English differ from each other in major ways, as much, perhaps, as the non-native varieties differ from the native varieties. Nevertheless native speakers of English appear to be mutually intelligible to a degree that does not extend to the nonnative varieties. Obviously, there are features that various native accents have in common, which facilitate their mutual intelligibility, and these features are not shared by non-native accents". Incidentally, Nihalani's observation stands the test of validity, although I find it difficult to fully agree with his view that two foreigners of the same nationality can communicate without any intelligibility problems. In this respect, Kenworthy (1987 cited in Walker 2001), proposes the idea of 'comfortable intelligibility' as a realistic goal. We could take this criterion to mean minimum general intelligibility or "what all speakers of all varieties have in common, which enables them to communicate effectively with speakers of native and non-native varieties other than their own".

This comfortable intelligibility is what Achebe (1965, p. 30) means when he says, 'the African writer should aim to use English in a way that brings out his message best without altering the language to the extent that its value as a medium of international exchange will be lost. He should aim at fashioning out an English which is at once universal and able to carry his peculiar experience.... it will have to be anew English, still in full communion with its ancestral home, but altered to suit its new surroundings'.

Brown (1989) classifies language features as (i) features that cause unintelligibility to non-native listeners from the same speech community as the speaker (for example, a Malaysian finds another Malaysian difficult to understand); (ii) features, which make it difficult for native listeners of English to understand non-native speakers (for example, an American finds it hard to comprehend a Japanese speaker of English); and finally, (iii) features, which lead to loss of intelligibility to non-native listeners from other speech communities ( for example, a Chinese listener of English finds it difficult to understand a Japanese speaker of English). Brown's second and third categories are similar to Melchers and Shaw's (2003, cited in Nunn 2005, p. 70) international intelligibility and his first category resembles their national intelligibility.

Seidlhofer (2001, cited in Burt 2005), observes that quite often it is features which are regarded as the most typically English, such as the agreement between a third person singular subject and its verb, tags, phrasal verbs and idioms, which turn out to be non-essential for mutual understanding. In a subsequent publication, Seidlhofer (2001) observes that certain traditionally serious errors do not hinder English as a lingua franca communication. According to Seidlhofer, these typical errors include (i) dropping the third person present tense $-\mathrm{s}$, (ii) confusing the relative pronouns 'who' and 'which', (iii) omitting articles where they are obligatory in native English language, and inserting them where they do not occur in English as a native language, (iv) failing to use correct forms in tag questions, e.g., 'isn't it?' or 'no?' instead of the ones used in standard British and American English, (v) inserting redundant prepositions, as in 'we have to study about...' ,' we have to discuss about...' (vi) overusing verbs of high semantic generality such as 'do', 'have', 
'make', 'put' and 'take', (vii) replacing infinitive constructions with 'that clause' as in 'I want that...', (vii) overdoing explicitness, e.g., 'black colour', and 'dead body' rather than just 'black' and 'body'. We may add several other features of Indian, Vietnamese, and Japanese varieties of English that do not cause unintelligibility. Such features are generally unproblematic and are no obstacle to communicative success.

As an alternative to inclusive and exclusive notions such as 'native' and 'non-native', Melchers and Shaw (2003, cited in Nunn 2005, p. 70), suggest international intelligibility (for example, an Indian and a Korean communicating effortlessly with each other), national intelligibility (for example, a Kashmiri and a Tamil interacting without any problem) and local intelligibility (for example, two Japanese people from Okinawa island or from Kyoto city interacting smoothly). Someone who knows some English but cannot communicate in it internationally, nationally or locally is an ineffective user of the language.

However, inaccurate pronunciation that is clearly understandable is forgiven whereas pronunciation that is not understood is, and must necessarily be, perfected if the speakers wish to be understood and if the listeners wish to understand, as this is the fundamental rule of communication (Offner 1995). Jenkins (2000) classifies the phonological features of EIL into core features and non-core features, essential in terms of intelligibility. According to her, divergences in the areas of vowel quality, weak forms, assimilation, and word stress from the native speaker realizations should be regarded as instances of acceptable L2 sociolinguistic variation. On the other hand, devoicing of consonants ('mug' pronounced as 'muck'), omission of consonants from clusters ('six' pronounced as 'sick')', confusion between short and long vowels (confusion between 'ship' and 'sheep'), substitution of the vowel as in 'bird' especially with the vowel in 'bard', and substitution of consonants and vowels by other consonants and vowels (' $\mathrm{TB}^{\prime}$ for 'TV'; 'snakes' for 'snacks'; 'hole' for 'hall' respectively). In her opinion, it is these features that play a significant role in international intelligibility.

Poor articulation of words can also affect intelligibility. For example, most Vietnamese and Japanese learners do not articulate words clearly. Vietnamese learners tend to drop word-final sounds. For instance, they will pronounce the italicized words in the following sentence almost identically, as if they were homophones:

"Mr. Nguyen, why (/wai/) doesn't your wife (/wai/) try white (/wai/) wine (/wai/ ) ?"

Whereas omission is a major problem with Vietnamese learners, substitution is a big problem with Japanese learners (Patil 2005, p. 7). For instance, there is a strong tendency among Japanese learners to replace /r/ with /l/, /v/ with /b/ and /f/ with /h/. As a result, it is very difficult to distinguish between 'This is a grass house' and 'This is a glass house'. An Arab learner's problems are substitution of sounds and insertion of extra sounds. So, 'pill' is articulated as 'bill' and 'text' is pronounced as 'tekist'. The pronunciation problems of the three groups of learners can be summarily illustrated with the help of the following single example:

"I'm going to dine with sixfriends. We'll have a pot of friedrice each". 
An Arab learner will most probably say, "I'm going to dine with sikis friends. We'll have a boat of rice each".

A Vietnamese learner will tend to say, "I'm going to die with sick friends. We'll have a pot of rice each".

A Japanese learner will likely say, "I'm going to dine with six hriends. We'll have a pot of flied lice each".

Thus mispronunciation of words such as 'dine' as 'die', 'six' as 'sick', 'friends' as 'hrends', 'pot' as 'boat', 'fried' as 'flied' and 'rice' as 'lice' may cause incomprehension or miscomprehension.

\section{Conclusion}

In short, we can say that unintelligibility concerns articulation or delivery of sounds, words, stress and intonation; incomprehensibility refers to culturespecific content and linguistic realization of politeness, conversational cooperation and nature of speech acts. Incomprehension may result from the use of new vocabulary and new use of existing vocabulary as well as certain turn taking patterns and deviant linguistic realization of speech functions such as coaxing, self-humbling, addresseeraising, etc. Unintelligibility may result from deviant pronunciation of certain sounds and words, and deviant word stress patterns. . The spread and growth of new varieties of English has led to development of new formal properties and functions which may cause incomprehension and unintelligibility.

\section{References}

(2006). A spoken test for pilots. Mumbai: The Times of India.
Achebe, C. (1965). English and the African Writer. Transition, 18, 27-30.

Achebe, C. (1975). The African Writer and the English Language. In Morning yet on creation day. London: Heinemann.

Bansal, R. K. (1969). The intelligibility of Indian English. Hyderabad: CIEFL.

Brown, A. (1989). Some thoughts on intelligibility. Retrieved April 10, 2018, from The English Teacher: http:// www.melta.org.my / ET / 1989/ main4.html

Burt, C. (2005). What is international English? Retrieved April 4, 2018, from Teachers' College, Columbia University Working Papers in TESOL \& Applied Linguistics: www.tc.columbia.edu/academic/ tesol/webjournal/pdf/Burt.pdf

Crystal, D. (1997). English as a global language. Cambridge: Cambridge University Press.

Dasgupta, P. (1993). The Otherness of English in India: India's auntie tongue syndrome. New Delhi: Sage Publications.

Graddol, D. (1997). The future of English. London: The British Council.

Jandt, F. E. (2001). Intercultural Communication. Sage Publications.

Jenkins, J. (2000). The Phonology of English as an international language. Oxford: Oxford University Press. 
Lee, J. J. (2005). The native speaker: an achievable model? Retrieved April 7, 2018, from http://www.asian-elfjournal.com/June_05)jl.php

McKay, S. L. (2002). Teaching English as an international language: rethinking goals and perspectives. New York: Oxford University Press.

Meierkord, C. (1998). Lingua Franca English: Characteristics of succesful non-native / non-native speaker discourse. Retrieved February 10, 2018, from http:// webdoc.sub.gwdg.de/edoc/ia/eese/ $\operatorname{artic} 98 /$ meierk/7_98.html

Melchers, G., \& Shaw, P. (2003). World Englishes: An introduction. London: Arnold.

Nair-Venugopal. (2003). Intelligibility in English: Of what relevance today to intercultural communication? Retrieved February 11, 2018, from Language and Intercultural Communication: www.multilingual-matters.net/laic/ 003/0036/laic0030036.pdf

Nihalani, P. (2000). Pragmatics of International Intelligibility. Asian Englishes, 3 (1), 108-113.

Nihalani, P. (1997). Vowel Phonology of Asian Englishes: Towards a characterization of "international English". Retrieved February 10, 2018, from http:/ / trill.berkley.edu/ICPhS/ frameless/errata/97.pdf
Nunn, R. (2005). Competence and teaching English as an international language. Retrieved February 15, 2018, from The Asian EFL Journal Quarterly: http:/ / w w w . a sian - journa 1. com / September_05_Ebook_editions.pdf

Offner, M. D. (1995). Communicating in English: Flexibility within a norm. Retrieved February 13, 2018, from Internet TESL Journal: http:// iteslj.org/Articles/OffnerCommunicating.html

Ojaide, T. (1987). My Poetry: English language and the African tradition. World Englishes, 6 (2), 165-167.

Patil, Z. N. (2002). Spoken English for Vietnamese Learners. Hanoi: The World Publishers.

Patil, Z. N. (2005). Twice-born languages: A perspective on English in Asia. A paper presented at Kyoto Conference on Asian Englishes. Kyoto University of Foreign Languages. Kyoto: Japan.

Pennycook, A. (1997). English and captial: some thoughts. Retrieved February 17, 2018, from The Language Teacher Online: http://jalt-publications.org/ tlt/files/97/oct/pennycook.html

Rao, R. (1938). Kanthapura. New Delhi: Orient Paperbacks.

Seidlhofer, B. (2003). A concept of international English and related issues: from 'real English' to 'realistic English'? Retrieved January 20, 2018, from Strasbourg: Council of Europe: http:/ 
/www.coe.int/T/E/cultural co p e r a tion / L a n g a g e s / Languagepolicy/policy

Seidlhofer, B. (2001). Closing a conceptual gap: The case for a description of English as a lingua franca. International Journal of Applied Linguistics, 11 (2), 133-158.

Smith, L. E., \& Nelson, C. L. (1985). International intelligibility of English: Directions and resources. World Englishes, 4, 333-342.

Soyinka, W. (1993). Art, dialogue and outrage: essays on literature and culture. New York: Pantheon Books.

Taylor, D. S. (2003). Who speaks English to whom? The question of teaching English pronunciation for global communication. Retrieved January 3, 2018, from http:/ / edu.leeds.ac.uk/-dst/inted/ global1.htm

Toolan, M. (1997). Recentering English: New English and global. English Today, 13 (4), 3-10.

Walker, R. (2001). Pronunciation for international intelligibility. Retrieved February 11, 2018, from http:// www.telus.net/linguisticsissues / internationalintelligibility.html

Yano, Y. (2001). World Englishes in 2000 and beyond. World Englishes, 20 (2), 119-131.
Yoneoka, J. (2000). Englishes in Asia. Retrieved December 15, 2017, from www2.kumagaku.ac.jp/teacher/judy/gyoseki/30AsianEnglish.doc

\section{Contributor}

Dr. Z. N. Patil has taught and delivered plenary talks and keynote addresses in twenty countries. He has several books and articles to his credit. These days he conducts workshops on ELT, soft skills and life skills in India and abroad. He is a founder member of the international group of scholars called 'English Scholars Beyond Borders'. 